\title{
UNSUR SOSIOLOGIS DALAM NOVEL SI ANAK KAMPOENG KARYA DAMIEN DEMATRA
}

\author{
Ahmad Muzaki \\ Prograam Studi Pendidikan Bahasa dan Sastra Indonesia \\ Fakultas Bahasa dan Seni, Universitas Indraprasta PGRI \\ J1. Nangka 58C, Tanjung Barat, Jakarta Selatan, Indonesia \\ ahmadmuzaki8@gmail.com
}

\begin{abstract}
Abstrak
Tujuan dari penelitian adalah untuk menganalisis unsur sosiologis dalam novel Si Anak Kampoeng karya Damien Dematra dan untuk mengungkapkan masalah-masalah sosial yang dialami para tokoh dalam novel. Selain itu, penulis berharap agar para pembaca lebih memahami isi dari novel ini._Metode penelitian yang digunakan untuk menganalisis novel ini adalah dengan menggunakan metode kepustakaan mengenai unsur ekstrinsik. Selain itu, penulis menggunakan pendekatan sosiologis dalam penyusunan langkah kerja. Setelah penulis menganalisis novel Si Anak Kampoeng melalui pendekatan sosiologis, akhirnya penulis menarik simpulan bahwa unsur sosiologis yang paling dominan pada novel $\mathrm{Si}$ Anak Kampoeng karya Damien Dematra adalah unsur Persuasif. Unsur Persuasif merupakan pendekatan yang berisi ajakan atau imbauan seseorang atau dua tokoh di tengah-tengah kehidupan sosial. Interaksi antartokoh yang terjadi dalam Novel Si Anak Kampoeng mencerminkan adanya interaksi yang baik di dalam masyarakat Desa Sumpur. Hal ini dapat diambil contoh setiap permasalahan di dalam masyarakat dalam novel Si Anak Kampoeng dapat diselesaikan dengan jalan musyawarah atau persuasif sehingga unsur persuasiflah yang paling banyak ditemukan dalam novel Si Anak Kampoeng
\end{abstract}

Kata kunci : Unsur Sosiologis, Novel Si Anak Kampoeng.

\begin{abstract}
The purpose of the study is to analyze sociological elements in the novel Si Anak Kampoeng by Damien Dematra to reveal the social problems experienced by the characters in the novel, except that the author hopes that the reader better understand the contents of this novel. The method used to analyze this novel method is to use the literature on extrinsic elements. Moreover, the authors use a sociological approach in the preparation of working steps. After the authors analyze the novel Si Anak Kampoeng through a sociological approach, the authors finally draw the conclusion that the sociological element most dominant on the novel Si Anak Kampoeng by Damien Dematra is persuasive element. Persuasive elements of an approach that contains an invitation or plea person or two characters in the midst of social life. Between leader interactions that occur in the novel Si Anak Kampoeng reflect their interaction both within the village community Sumpur. It can take a sample every problem in society in the novel Si Anak Kampoeng can be resolved by consensus or a persuasive way. So persuasive elements most commonly found in the novel Si Anak Kampoeng.
\end{abstract}

Keywords: Elements of sociological, Novel Si Anak Kampoeng

\section{PENDAHULUAN}

Sastra adalah ungkapan dari seorang pengarang atau pencipta karya satra yang dituangkan dalam bentuk lisan dan tulisan. Sastra merupakan hasil buah pikiran pengarang dari apa yang dilihat, didengar, dan dibacanya yang kemudian dipadukan dengan 
imajinasi-nya. Satra merupakan suatu kreativitas manusia dalam mengekspresikan diri manusia tersebut. Dalam menjalani kehidupan sehari-hari manusia pasti membutuhkan bantuan orang lain, sehingga manusia sering kita kenal sebagai makhluk sosial, karena dalam bersosialisasi manusia pasti menemukan suka dan duka.

Sastra menyajikan kehidupan, dan sebagian kehidupan terdiri dari kenyataan sosial. Sastra merupakan sebuah perwakilan perasaan dari hasil perenung-an panjang. Dalam menciptakan karya sastra, seorang pengarang menyampai-kan ide-ide atau gagasan yang baru. Sastra adalah suatu ekspresi yang dituangkan dalam bentuk tulisan pada saat pengarang berada pada saat itu.

Dalam wujudnya, karya sastra itu mempunyai dua aspek penting. Dua aspek penting tersebut mencakup isi dan bentuk. Isi karya sastra adalah tentang pengalaman hidup manusia, sedangkan bentuk adalah segi-segi yang menyangkut cara penyampaian, yaitu cara sastrawan memanfaatkan bahasa yang indah untuk mewadahi isinya.

Hasil karya sastra tidak hanya menyajikan hal-hal yang indah dan menyenangkan saja. Tetapi karya sastra menyajikan hal-hal yang menyedihkan, memuakkan, bahkan menjijikan. Kata seni mempunyai arti yang begitu luas dari pada arti kata indah. Sebagai karya kreatif, sastra harus mampu melahirkan suatu kreasi yang indah dan berusaha menyalurkan kebutuhan keindahan manusia. Di samping itu, sastra harus mampu menjadi wadah penyampaian ide-ide yang dipikirkan dan dirasakan oleh sastrawan tentang kehidupan umat manusia.

Karya sastra dalam bentuk novel menampilkan kenyataan sosial, dalam hal ini terdapat interaksi antara individu dengan individu, hubungan individu dengan masyarakat, maupun proses interaksi yang terjadi pada diri manusia tersebut. Dalam menciptakan karya sastra, seorang pengarang atau sastrawan tidak terlepas dari kondisi sosial yang melatar belakanginya. Karya sastra merupakan ungkapan pribadi seorang pengarang yang diciptakan kepada pe-nikmat karya sastra sebagai pengetahuan dari pengalaman pribadinya atau dari daya imajinasinya.

Unsur sosiologis yang terdapat dalam novel Si Anak Kampoeng karya Damien Dematra sangat terasa sekali ketika kita telah membaca novel tersebut. Unsur sosiologis tersebut seperti unsur komunikasi, yang menjelaskan bagaimana tokoh utama mengadakan hubungan dan komunikasi dengan tokoh yang lain atau masyarakat sekitar. Unsur adaptasi dalam novel tersebut menjelaskan bagaimana tokoh utama menyesuaikan diri dengan keadaan atau lingkungan di dalam masyarakat. Unsur persuasif dalam novel tersebut menjelaskan bagaimana tokoh utama mempengaruhi tookohtokoh yang lain atau tokoh lain dalam mempengaruhi tokoh utama. Unsur harmoni dalam novel tersebut menjelaskan suatu pernyataan rasa, aksi, gagasan dan minat keselarasan dan kesesuaian tokoh utama terhadap tokoh-tokoh yang lain. Dan unsur konflik dalam novel tersebut menjelaskan bagaimana ketegangan dan pertentangan yang melibatkan tokoh utama.

Mengacu pada latar belakang tersebut, penulis tertarik untuk meneliti unsur sosiologis dalam novel Si Anak Kampoeng karya Damien Dematra. Penelitian ini didasari pada simbolsimbol sosiologis yang kental dan menarik yang disajikan dalam novel $\mathrm{Si}$ Anak Kampoeng karya Damien Dematra. Sebagai novel sosial, novel ini memiliki muatan unsur-unsur sosiologis 
yang mencerminkan nilai dan norma sosial yang berlaku di masyarakat.

Unsur sosiologis menjadi bagian dari unsur ekstrinsik karya sastra. Unsur sosiologis menekankan pada dimensi sosial yang disajikan dalam cerita sastra. Nilai-nilai dan norma kemasyarakatan menjadi acuan dalam unsur sosiologis sastra. Hubungan antara satu tokoh dengan tokoh lainnya, hubungan antar-masyarakat yang dikisahkan dalam cerita sastra menjadi indikator unsur sosiologis sastra. Segala aktivitas keseharian yang dilakukan tokoh dalam cerita sastra serta proses sosialnya menjadi bagian yang dikaji dalam unsur sosiologis sastra.

Sosiologi adalah telaah tentang lembaga dan proses sosial manusia yang objektif dan ilmiah dalam masyarakat. Masyarakat adalah salah satu objek dari munculnya sastra. Sesungguhnya karya sastra itu lebih banyak dipengaruhi oleh masyarakat. Sedangkan masyarakat lebih sedikit kemungkinan dipengaruhi karya sastra. Sastrawan hanya sebagai kreator mempersiapkan kerangka dan sistem naratif (Hanum, 2005:29).

Sosiologi sastra adalah cabang penelitian sastra yang bersifat reflektif. Penelitian ini banyak diminati oleh peneliti yang ingin melihat sastra sebagai cermin kehidupan masyarakat. Arena-nya, asumsi dasar penelitian sosiologi sastra adalah kelahiran sastra tidak dalam kekosongan sosial. Kehidupan sosial akan menjadi picu lahirnya karya sastra. Karya sastra yang berhasil akan sukses yaitu yang merefleksikan zamannya. (Endraswara, 2003:77).

Sosiologi bersifat kognitif, sedang sastra bersifat afektif. Masalah pokok sosiologi sastra adalah karya sastra itu sendiri, sebagai aktivitas kreatif dengan ciri yang berbeda-beda (Ratna, 2002:8). Dengan cara yang kreatif maka timbullah karya sastra yang imajinatif.
Karya sastra memiliki tujuan akhir yang sama, yaitu sebagai motivator ke arah aksi sosial yang lebih bermakna, sebagai pencari nilai-nilai kebenaran yang dapat mengangkat dan memperbaiki situasi dan kondisi alam semesta (Ratna, 2002:35)

Wellek dan Warren (2002:4) menyatakan bahwa "sosiologi adalah suatu telaah sosiologi terhadap suatu karya sastra". Telaah sosiologi ini mempunyai 3 klasifikasi, yaitu 1) Sosiologi pengarang yaitu berbicara tentang status sosial, ideologi politik dan lain-lain yang menyangkut diri pengarang. 2) Sosiologi karya sastra yaitu berbicara tentang suatu karya sastra yang menjadi pokok telaah-an adalah tentang apa yang tersirat dalam karya sastra tersebut dan apa tujuan atau amanat yang hendak disampaikannya. 3) Sosiologi sastra yaitu berbicara tentang pembaca dan pengaruh sosialnya ter-hadap masyarakat. Adapun Unsur-unsur sosiologis, yaitu komunikasi, adaptasi, persuasi, harmoni, dan konflik.

Melihat beberapa pendapat di atas, dalam penelitian ini dapat dikatakan bahwa sosiologi sastra adalah suatu pendekatan yang mempertimbangkan segi-segi kemasyarakatan. Dalam telaah sosiologi terhadap sastra yakni: pertama bahwa sastra merupakan cermin proses sosial ekonomi belaka. Kedua, pen-dekatan yang mengutamakan teks sastra sebagai penelaahan. Yang lebih penting lagi, penelitian sastra diharapkan mampu mengungkap fenomena di balik obyek sastra sebagai ungkapan hidup manusia. (Endaswara, 11:2013).

Menurut Abrams dalam Nurgiyantoro (2002:9) "sebutan novel dalam bahasa Inggris-dan inilah yang kemudian masuk ke Indonesia-berasal dari bahasa Itali novella (yang dalam bahasa Jerman: novelle). Secara harfiah novella berarti 'sebuah barang baru 
yang kecil', dan kemudian diartikan sebagai 'cerita pendek dalam bentuk prosa'.

Kehadiran bentuk novel sebagai sebuah sastra berawal dari kesustraan Inggris pada awal abad ke-18. Timbul akibat berawal pengaruh tumbuhnya filsafat yang dikembangkan John Locke (1632-1704) yang menekankan pentingnya fakta atau pengalaman, dan lahannya berfikir secara fantastik. Pentingnya belajar dari pengalaman merupakan ajaran baru yang berkembang pada masa itu. Akibat timbulnya para pembaca karya sastra dari kalangan menyukai puisi dan drama dianggap tidak realitas.

Dalam novel diungkapkan katakata yang dirangkai sedemikian rupa sehingga dapat dijadikan sebagai suatu pandangan mengenai dunia sosial. Dengan demikian dapat disimpulkan bahwa novel merupakan sebuah karya sastra yang menceritakan suatu kejadian luar biasa yang ada dalam kehidupan manusia yang melahirkan konflik, sehingga terjadi perubahan jalan hidup tokoh-tokohnya. Novel menyajikan suatu pandangan mengenai hubungan kita sebagai pembaca mengisahkan kejadian sesuai dengan keadaan zaman pada saat ini.

Dari segi jenisnya, novel terdiri dari novel sastra dan novel populer. Novel sastra cenderung mengutamakan cerita-cerita yang terkait dengan kisah kehidupan manusia. Sedangkan novel populer cenderung mengedepankan aspek-aspek yang terjadi dalam realitas kehidupan manusia sebagai cerminan kelompok sosial tertentu. Novel merupakan kisah kehidupan yang kompleks. Selain itu, karya sastra berbentuk novel lebih menonjolkan individual tokoh dalam cerita, di samping berorientasi pada kehidupan yang berkembang di tengah masyarakat.
Novel dapat dikatakan sebagai karya sastra yang komprehensif dengan menampilkan berbagai macam tema, memiliki berbagai macam alur atau plot dan menggambarkan karakter tokoh yang bervariasi dengan suasana yang beragam. Novel merupakan karya sastra yang mengisahkan perjalanan nasib para tokohnya hingga menimbulkan konflik dan menyajikan adanya perubahan nasib pelaku. Novel dapat dikatakan kisah penggalan kehidupan manusia, di samping menyajikan konsentrasi cerita pada saat yang tegang. Karya sastra berbentuk novel juga menjadi cerminan realitas sosial.

\section{METODE PENELITIAN}

Dalam penelitian ini, peneliti menggunakan pendekatan penelitian deskriptif kualitatif. Pendekatan deskriptif kualitatif adalah pendekatan yang menggambarkan analisis hasil yang akan diteliti dengan sistem yang berbentuk kata-kata atau simbol. Pada penelitian kualitatif, penelitian dilakukan pada objek yang alamiah, yakni objek yang berkembang apa adanya, tidak dimanipulasi oleh peneliti dan kehadiran peneliti tidak begitu memengaruhi dinamika pada objek tersebut. Selain itu, penulis menggunakan pendekatan sosiologis dalam penyusunan langkah kerja.

Teknik penelitian yang digunakan adalah teknik analisis isi (content analysis) dengan metode kepustakaan. Fokus penelitian ini terletak pada kutip-an dalam novel tersebut yang memuat unsur sosiologis. Adapun tahap pen-catatan datanya yaitu: membaca novel, mengidentifikasi unsur sosiologis, menganalisis data, menginterpretasi data, membahas hasil temuan, dan me-nyimpulkan hasil penelitian. Keabsahan data dilakukan dengan menggunakan teknik 
triangulasi, yaitu teknik pengujian kredibilitas yang diartikan sebagai pengecekan data dari berbagai sumber dengan berbagai cara dan waktu.

\section{HASIL DAN PEMBAHASAN}

Adapun kandungan unsur sosiologis dalam novel Si Anak Kampoeng karya Damien Dematra dapat dideskripsikan sebagai berikut.

1. Ia berjalan ke rumah ayahnya. Tapak-tapak kakinya berderak di antara batu-batuan yang dilewatinya, melewati dinding rumahnya. Ia melihat tulisan tangan di dinding kayu yang telah dimakan ngengat. 31 Mei 1935. Tulisan itu semacam sebuah catatan kecil Rahima, sebagai pengingat kelahiran adiknya. Dan Syafii yang sering melewati daerah itu mengingat hal itu.

Kalimat di atas termasuk unsur harmoni karena kalimat di atas terdapat suatu pernyataan rasa, aksi dan gagasan dan kesesuaian tokoh utama yakni Syafii dengan Rahima.

2. Syafii melihat satu pasukan ternak telah menunggunya, dan ia tersenyum. Ayam-ayamnya berceloteh dengan ribut dari bawah rumah panggung itu. Dari sekitar lima ekor ayam, ada satu yang sangat disayanginya. Si jago.

Kalimat diatas menunjukan unsur adaptasi yang terjadi antara Syafii dengan keadaan atau lingkungan di dalam masyarakat.

3. Kepalanya yang berambut lembut menunduk. "Maaf. Aku tidak bermaksud mendengarkan percakapan kalian."

"masuklah, Pi'i” Etek Lamsiah memanggilnya. Ia terlihat agak malu.

Kalimat di atas menunjukkan unsur persuasif. Tokoh utama yakni
Syafii mendapat pengaruh dari Etek Lamsiah untuk masuk ke dalam rumahnya.

4. Syafii selalu senang mendengar kata ayahnya. Setelah dirinya masih banyak saudara yang dimilikinya, namun ayahnya selalu memperhatikan keluarganya dengan baik. Pria itu adalah seorang yang bertanggung jawab, dan Syafii sangat menyayanginya dan menghormatinya-sekalipun kalau mereka sedang bersama, ia tidak banyak bicara.

Kalimat di atas termasuk unsur harmoni karena tokoh utama dalam novel tersebut yakni Syafii memiliki kesatuan rasa dengan bapaknya.

5. "Selasa akhir bulan ini, waktu hari pasar di Kumanis, Oncu akan pergi, kamu mau ikut?" tanyanya pada Syafii. "Bapakmu juga pasti akan pergi."

Syafii mendongak dengan bersemangat mendengarnya. Mau? Ia mau sekali!

Kalimat di atas termasuk unsur persuasif karena Syafii mendapat ajakan untuk pergi ke pasar bersama Oncu Wahid. Dan Syafii ikut dengannya ke pasar Kumanis.

6. Dalam ketenangan, ia dapat membaca dan mengingat semuanya dengan baik, dan ia melakukannya hampir setiap malam. Biasanya, dalam kamarnya. Rumah itu cukup besar, karena Syaiful terkadang masih tidur dengan Bainah dan Wahid, maka Syafii memiliki ketenangan dan keleluasaan.

Kalimat di atas termasuk unsur adaptasi karena Syafii dapat me-nyesesuaikan dirinya dengan keada-an lingkungan sekitarnya. Dan Syafii mendapat ketenangan dalam belajar hampir setiap malam 
ketika keluarga Oncu Wahid sudah tertidur.

7. "Ikuti gerakan bapak, ya?"

Syafii mengangguk dan menunggu, memperhatikan. Pada akhirnya, ayahnya mengemudikan perahunya sendiri, karena riak sungai tidak terlalu kencang dan mereka segera tiba di sebuah sungai yang airnya lebih tenang.

Kalimat di atas termasuk unsur persuasif atau ajakan yang melibat-kan tokoh utama yakni Syafii. Syafii mendapat pengaruh dari ayahnya untuk mengikuti gerakan ayah. Nafasnya terengahengah karena bersemangat, tangannya melambai-lambai di udara dengan penuh semangat dalam mengemudikan perahunya.

8. "Teman-teman!" Syafii berteriak lincah sambil berlari di atas tanah yang agak lembap dan berumput.

Kalimat di atas termasuk unsur adaptasi yang melibatkan Syafii dan teman-temannya dalam bermain bersama.

9. "Kamu habis berenang?" tanya Nalam, memperhatikan anaknya, dan Zainal mengangguk.

"Dengan Pi'i?" tanya Rahima lagi, dan Zainal lagi-lagi mengangguk, tidak terlalu berminat untuk menjawab saat makanan di depannya terlihat sangat menggiurkan. Ia baru menyadari bahwa perutnya sangat lapar.

Kalimat di atas termasuk unsur komunikasi yang terjadi antara Zainal dengan ibunya. Nalam me-nanyakan kepada Zainal setelah ia pulang berenang dengan Syafii dan teman-temannya.

10. Syafii tidak ingin dianggap sebagai si tukang cari muka lagi sehingga ia menunduk saja.

Kalimat di atas termasuk unsur adaptasi karena dalam adegan ter-sebut menceritakan pertentangan yang terjadi di dalam kelas. Syafii yang selalu menjwab pertanyaan dari sang guru malah dibenci dengan anak kota Sumpur. Untuk me-nyesesuaikan diri, maka Syafii lebih baik menunduk saja.

11. "Huh! Cari muka!" bisik tajam Bahri, seorang anak dari Kota Sumpur Kudus. Syafii mengacuhkan si anak si bibir tajam itu. Ia sudah terbiasa mendengarkan cemoohan anak-anak kota Sumpur Kudus. Bagi anak-anak dari desa Calau, mereka yang dari kota Sumpur Kudus memang dianggap lebih sombong entah karena kelebihan apa.

Kalimat di atas termasuk unsur konflik karena terdapat pertentangan yang terjadi antara anak-anak kota Sumpur Kudus dengan anak-anak dari Desa Calau. Pertentangan yang terjadi disaat kegiatan belajar ber-langsung di dalam kelas.

12. Perkelahian antar pelajar, seumur hidupnya, Syafii tidak pernah beradu otot. Ia lebih mengembangkan kemampuan berpikirnya, dan maksimalkemampuan berstrategi, mengukur dan menganalisa, seperti yang dilakukannya saat sabung si jago.

Kalimat di atas termasuk unsur adaptasi. Kalimat di atas menjelas-kan bagaimana tokoh utama yakni Syafii menyesesuaikan dirinya dengan lingkungan di sekitarnya. Syafii lebih mengembangkan ke-mampuan berpikirnya daripada beradu otot.

13. Syafii menatap sahabatnya dan kemudian mendesah pasrah, melangkahkan kakinya untuk pulang. "yuk," ajakanya dan langkah kaki mereka berhenti setelah 
melenggang tidak sampai satu meter.

Kalimat di atas termasuk unsur persuasi, ajakan yang terjadi dalam cerita menjelaskan bahwa Syafii mempengaruhi temantemannya untuk pulang kerumah.

14. "Jalan damai, Bodoh!" Hasan tak tahan lagi. Urat sarafnya sudah terlalu tegang, dan ia harus melampiaskannya pada sesuatu. Zainal, yang berada di sebelahnya, melirik setengah geli pada wajah culun yang cerdas tapi penakut itu.

"Heh! Kamu! Nantang aku, yo!" Jamal telah tiba di depan dan menatap mata kelima anak Calau itu satu persatu.

Kalimat di atas merupakan unsur konflik karena pada adegan cerita di atas terdapat suatu ketegangan dan pertentangan yang terjadi antara anak Desa Sumpur Kudus dan Kota Calau.

15. Ketiga kawannya hanya mendesah. Mendengar kata-kata Syafii, yang walau diucapkan dengan santai, namun penuh makna dan tegas itu, akhirnya mereka mengambil perahunya kembali dan menolong Hasan yang telah bergetar di pinggir sungai.

Kalimat di atas termasuk unsur harmoni karena terdapat suatu pernyataan rasa, aksi, dan gagasan yang melibatkan tokoh utama. Syafii yang selalu memberikan pendapat kepada teman-temannya dan kemudian teman-temannya tersebut mengikutinya.

16. Syafii, yang berada paling dekat dengannya, berusaha meraih tubuhnya. Karena tarikan Hasan padanya, ia pun jadi ikut-ikutan jadi merasa timbul tenggelam, karena Hasan menyeret dan mencengkeramnya sebegitu kuat. Zainal dan Julai egera membantunya. Julai memegang lengan kanan Syafii, sementara Zainal membantu menariknya dari depan, sementara Makdiah memegang Syafii agar tidak tenggelam.

Kalimat di atas termasuk unsur persuasi karena terdapat suatu pengaruh atau ajakan tokoh utama kepada tokoh yang lain. Kejadian pada kalimat di atas terjadi saat Syafii dan teman-temannya menolong Hasan yang hendak tenggelam di sungai.

17. "Ah, Onga dan Oncu-mu sangat merindukanmu, Pi'i! Sudah lama ang tidak mampir untuk belajar menembak!"

"Oh ya.." Syafii mengangguk, tersenyum. "Ya, awak juga rindu. Awak akan ajak bapak kesana."

Onga Sarikayo mengibaskan tangan. "Ah! Bapakmu itu! Orangnyo sibuk sekali...Onga mampir, dianyo ndak ado."

Kalimat di atas termasuk unsur komunikasi karena dalam cerita di atas terdapat adanya percakapan yang terjadi antara Syafii dengan Oncu Sarikayo.

18. Syafii mengernyit. "Ndak, ndak apoapo, Etek. Hanya luka sedikit." Syafii menarik lengannya, namun toh, ia tetap membiarkan Bainah meraih lengannya yang berdarah, kemudiannya menyiramnya dengan air garam.

Kalimat di atas termasuk unsur persuasif yang melibatkan Syafii dengan Etek Bainah. Saat itu Syafii diobati oleh Etek Bainah karena Syafii habis bertengkar dengan anak Calau yang menjadikannya sebagian tubuhnya luka.

19. "Tadi awak bacakak dengan temanteman dari Sumpur." 
"kamu?" terdapat nada humor dalam cara ayahnya mengucapkan kalimatnya. "Iya. Awak," Syafii menatap ayahnya

Di luar dugaanya, ayahnya tersenyum. "Kamu sudah jera sekarang?" tanya Ma'rifah. "Bagaimana rasanya adu otot?"

Syafii mengernyit, "sakit, pak. Ndak enak."

Kalimat di atas termasuk unsur komunikasi, pada kalimat di atas adanya komunikasi yang terjadi antara Syafii dengan Ma'rifah. Syafii menceritakan kejadian pertengkaran-nya dengan anak Calau kepada Ma'rifah.

20. "Ya, pak," Syafii mengangguk dengan patuh. Segara setelah selesai makan, Ma'rifah memegang tangan Syafii dan menuntunnya. "Ayo, bapak temani kamu kembali ke rumah."

Syafii mengangguk, selalu merasa aman apabila sedang berada bersama ayahnya, sekalipun di kejauhan terdengar bunyi auman harimau.

Kalimat di atas termasuk unsur persuasi, karena terdapat ajakan yang melibatkan tokoh utama dengan Ma'rifah. Saat itu Syafii ditemani ayahnya untuk kembali ke rumahnya. Ayah Syafii menuntun-nya agar Syafii tidak takut lagi dari keadaan di sekitarnya.

21. "Bapak indak takut samo apo yang jauh, Nak. Bapak berpikir tentang apo yang di depan mato. Bapak indak mau memusingkan hal yang indak perlu. Kadang-kadang, ketakutan bisa lebih besar daripada masalah yang ditakuti."

Kalimat di atas termasuk unsur adaptasi. Syafii mendapatkan nasihat dari ayahnya agar Syafii tidak takut dengan masalah yang harus dihadapinya. Dan Syafii dapat menyesesuaikan dengan keadaan yang ada. Unsur adaptasi di sini sangat terasa dengan disertainya sikap Syafii dan ayahnya yang meyakinkan agar Syafii tidak mudah takut terhadap persoalan hidup.

22. "Nanti malam, jangan lupa ke surau, ya, Pi'i?" Oncu Wahid yang telah bergabung bersama mereka, berkata sambil menyuapkan nasinya dengan lahap.

"Oncu ngajar ngaji?" tanya Syafii, dan Oncu Wahid mengangguk. Pria muda itu menatap Hasan. "Kamu juga ikut saja. Belajar Al Quran.”

Kalimat di atas termasuk unsur persuasif. Oncu Wahid mengajak Syafii dan Hasan untuk pergi ke surau untuk belajar Al Quran bersama. Dalam penggalan kalimat di atas terdapat hubungan yang baik antara Syafii dan orangorang yang ada di sekitarnya.

23. Oncu yakin, kamu sudah cukup dewasa. Terdapat kesungguhan dalam kata-katanya, dan Syafii mengangguk. "Kamu boleh melepas-nya, hanya dalam bahaya, yo?"

Syafii mengangguk, merasa dipercaya. "Awak ndak akan ngecewain Oncu." Ia memeluk Naksan dengan erat.

Kalimat di atas termasuk unsur harmoni. Dalam kalimat di atas terdapat suatu pernyataan rasa, aksi, gagasan dan minat yang diungkap-kan antara Syafii dengan Oncu Naksan. Syafii merasa dipercaya oleh Oncu Naksan karena Syafii merasa sudah dewasa. 


\begin{tabular}{|c|c|}
\hline \multicolumn{2}{|c|}{ Unsur Sosiologis } \\
\hline Komunikasi & Harmoni \\
\hline 11 adegan & 12 adegan \\
\hline Persentase & $21,73 \%$ \\
\hline $\begin{array}{l}\text { Berdasarkan data temuan analisis } \\
\text { unsur sosiologis dalam novel Si Anak } \\
\text { Kampoeng karya Damien Dematra, } \\
\text { tampak jelas unsur-unsur sosiologis } \\
\text { yang terdapat dalam novel tersebut } \\
\text { lebih banyak mengacu pada unsur } \\
\text { Persuasif dan unsur komunikasi. Kedua } \\
\text { unsur tersebut dapat diketahui bahwa } \\
\text { unsur persuasif dan komunikasi dalam } \\
\text { novel Si Anak Kampoeng karya Damien } \\
\text { Dematra menggambarkan bahwa tokoh } \\
\text { utama yakni Syafii mampu } \\
\text { mempengaruhi lawan bicara atau }\end{array}$ & $\begin{array}{l}\text { memperoleh data sebanyak 19,56\%, dan } \\
\text { unsur konflik memperoleh data } \\
\text { sebanyak 8,69\%. 2) Novel Si Anak } \\
\text { Kampoeng karya Damien Dematra } \\
\text { merupakan gambaran sosiologis. } \\
\text { Tercermin dari unsur-unsur yang terjadi } \\
\text { dalam kehidupan Syafii. Dominasi } \\
\text { unsur sosiologis pada novel tersebut } \\
\text { adalah unsur persuasif, kehidupan } \\
\text { Syafii yang mendapat pengaruh atau Ia } \\
\text { mempengaruhi tokoh dalam novel } \\
\text { sangat memberikan pelajaran yang } \\
\text { bermanfaat dalam hidupnya. }\end{array}$ \\
\hline
\end{tabular}
masyarakat Desa Sumpur Kudus. Keinginan Syafii untuk mengenyam pendidikan yang lebih tinggi dapat terealisasikan dengan kegigihan yang ia tanamkan dalam dirinya, dibuktikan secara nyata dengan sikapnya yang mampu beradaptasi dengan siapa pun selama mengenyam pendidikan.

\section{SIMPULAN}

Setelah penulis meneliti dengan saksama analisis unsur sosiologis novel Si Anak Kampoeng karya Damien Dematra dapat disimpulkan sebagai berikut. 1) Kecenderungan unsur dominan yang muncul dalam novel $\mathrm{Si}$ Anak Kampoeng Karya Damien Dematra adalah unsur persuasif dan unsur komunikasi. Dapat dilihat dari jumlah kutipan dalam deskripsi temuan peneliti-an, unsur persuasif memperoleh data sebanyak 26,08\%, unsur komunikasi memperoleh data sebanyak $23,91 \%$, unsur harmoni memperoleh data sebanyak $21,73 \%$, unsur adaptasi

\section{DAFTAR PUSTAKA}

Dematra, D. (2010). Si Anak Kampoeng. Jakarta: Gramedia Pustaka Utama.

Endraswara, S. (2003). Metodologi Penelitian Sastra. Jakarta: Pustaka Widya Utama.

(2011). Metode Penelitian Sastra. Yogyakarta: CAPS

Hanum, Z. (2005). Kesustraan Banding. Malaysia : Rahmah SDN. BHD.

Nurgiyantoro, B. (2002). Teori pengkajian fiksi. Yogyakarta: Gadjah Mada University Press.

Ratna, N. K. (2002). Paradigma Sosiologi Sastra. Yogyakarta: Pustaka Pelajar.

Wellek, R. \& Warren, A. (2002). Teori Kesustraan. Jakarta : PT Gramedia. 